\title{
Delayed metamorphosis of amphibian larvae facilitates Batrachochytrium dendrobatidis transmission and persistence
}

Daniel Medina ${ }^{1}$, Trenton WJ Garner ${ }^{2}$, Luis María Carrascal ${ }^{3}$ and Jaime Bosch ${ }^{3,4^{*}}$

${ }^{1}$ Department of Biological Sciences, Derring Hall 2119, Virginia Tech, Blacksburg, VA 24061, USA

${ }^{2}$ Institute of Zoology, Regent's Park, London NW1 4RY, United Kingdom

${ }^{3}$ Museo Nacional de Ciencias Naturales, CSIC, José Gutiérrez Abascal 2, 28006 Madrid, Spain

${ }^{4}$ Centro de Investigación, Seguimiento y Evaluación, Parque Nacional de la Sierra de Guadarrama, Cta. M-604, Km. 27.6, 28740 Rascafría, Spain

Running Head: Amphibian long-lived larvae and chytridiomycosis

Key Words: Batrachochytrium dendrobatidis; delayed metamorphosis; intraspecific reservoir; overwintered larvae; pathogen transmission

\section{Corresponding Author:}

Email address: bosch@mncn.csic.es

Phone number: +34 914111328, ext. 1228

Fax number: +34 915645078 


\section{ABSTRACT}

2 Highly virulent pathogens that cause host population declines confront the risk of fade-out, but if 3 pathogen transmission dynamics are age-structured, pathogens can persist. Among other features of amphibian biology, variable larval developmental rates generate age structured larval populations, which in theory can facilitate pathogen persistence. We investigated this possibility empirically in a population of Salamandra salamandra in Spain affected by Batrachochytrium dendrobatidis $(B d)$ at breeding sites that lacked alternative amphibian hosts. None of the adults presented infection by $B d$.

However, for the larvae, while environmental heterogeneity was the most important predictor of infection, the effect on infection dynamics was mediated by transmission from overwintered larvae to new larval recruits, which occurred only in permanent larval habitats. We suggest that interannual $B d$ maintenance in a host population that experiences mass mortality associated with infection can occur without an environmental reservoir or direct involvement of an alternative host in our study system. However the two aquatic habitat types that support intraspecific reservoirs, permanent streams and ponds, are not ideal habitats for long-term $B d$ maintenance, either due to poor transmission probability or low host survival respectively. While intraspecific pathogen maintenance due to larval plasticity might be possible at our study sites, this transmission pattern is not without significant risk to the pathogen. The availability of alternative hosts nearby does indicate that permanent $B d$ fade-out is unlikely. 
Emerging infections are increasingly associated with high levels of host mortality followed by persistent host decline or local extirpation (De Castro \& Bolker 2005, Fisher et al. 2012). Pathogens causing catastrophic host responses are put at risk by the rapid, large-scale decline in primary host density, which might reduce the likelihood of successful pathogen transmission (Briggs et al. 2010). Pathogens can compensate against this risk of fade-out (i.e. the pathogen is lost from the host population below a density threshold, Bartlett 1960) by exploiting alternative hosts or by environmental persistence outside of a host (De Castro \& Bolker 2005, Garner et al. 2006). However, both of these strategies also entail risk for the pathogen. Alternative hosts can exhibit significant resistance to infection (Agrawal 2000) and intraspecific contacts may be significantly more likely than interspecific contacts, reducing the opportunity for interspecific transmission events (RuizGonzález et al. 2012). Similarly, environmental pathogen stages may not survive for extended periods of time outside of a host, or withstand shifts in environmental conditions (Fuller et al. 2012).

Pathogens can compensate for these risks by adopting strategies that allow them to exploit the primary host exclusively even when causing it to suffer mass mortality. As long as host mortality remains low enough to allow at least some new infections to occur (i.e., the pathogen's basic reproductive ratio $\mathrm{R}_{0}>1$ ), even highly virulent and generalist pathogens can be maintained in a single host system (Briggs et al. 2010). Within this context, the ecological setting (e.g. different habitats) may offer opportunities for virulent pathogens and highly susceptible hosts to coexist even when hosts experience mass mortalities. Moreover, if host mortality is age-dependent, and survival of the susceptible age class allows for sufficient recruitment into older age classes, high rates of age-specific mortality may be tolerated and infection maintained in the single host species population as has been observed in the infection dynamic between the larvae of tiger salamanders (Ambystoma tigrinum stebbinsi) and Ranavirus, ATV (Brunner et al. 2004).

Typically, larval amphibians either accelerate development in response to environmental risk or delay metamorphosis in resource-constrained environments until sufficient resources are accrued to ensure 
increased post-metamorphic survival exceeding that experienced by those that do not delay metamorphosis (reviewed in Wells 2007). Thus, it is not uncommon, due to either developmental plasticity or multiyear larval period, for different cohorts of larvae to overlap in the same environment, potentially offering pathogens the opportunity to be transmitted amongst age classes.

The fungus Batrachochytrium dendrobatidis $(B d)$, which causes the emergent infectious disease chytridiomycosis, has been implicated in amphibian population declines and extinction worldwide (Fisher et al. 2012). In the $B d$-amphibian host system, age-specific transmission dynamics amongst dissimilar age classes has been examined mathematically by Briggs et al. (2010) in an American anuran species. Maintenance of $B d$ in an anuran population facilitated by a larval reservoir has also been postulated for another anuran species in Europe (Walker et al. 2010). Although postmetamorphic mortality was and continues to be extremely high in both species, host population persistence is a strong indication that at some locations enough animals survive to adulthood to enable population persistence (Briggs et al. 2010, Walker et al. 2010).

In the amphibian- $B d$ system, while a role for delayed maturation of early developmental stages in pathogen maintenance has been justified mathematically (Briggs et al. 2005), empirical data in support of theory are scant. This is because delayed development is exhibited by some larvae in all populations described in Briggs et al. (2010) and at all high-elevation sites studied by Walker et al. (2010), and potential alternative hosts occur in both systems (Reeder et al. 2012). To ascertain if host developmental plasticity is a key factor in pathogen maintenance, it would be necessary to compare infection dynamics across geographically proximate populations with and without delayed metamorphosis and eliminate the potential for pathogen maintenance via alternative hosts.

Here we report a comparative study of infection dynamics in larval populations of the fire salamander, Salamandra salamandra. At high elevation sites in Western Europe, larvae of this species commonly delay metamorphosis and overwinter in water at rearing sites. However, at some of these locations water may be ephemeral, obliging larvae to complete metamorphosis in the same season that they were deposited into the water. In Guadarrama National Park of Spain, infection with 
$B d$ causes both pre- and post-metamorphic mortality (Bosch \& Martínez-Solano 2006). After the local extirpation of Alytes obstetricans in the study area (Bosch et al. 2001), fire salamander larvae became the sole occupants of many larval rearing sites throughout the year (Bosch, unpublished data), and the natural history of the species ensures that only female adults make contact with rearing sites, and then only fleetingly (Wake 1993, Schmidt et al. 2007). In our study, we used field data of larval infection to determine if infection in cohorts of new (young of year, YoY) larvae could be the result of cohabitation with infected, overwintered (OW) larvae. We also examined how interactions between YoY and OW larvae were affected by rearing site hydrology (ponds vs. streams) and sampled adults to see if they act as potential pathogen reservoirs in the system. In order to place pathogen dynamics in a broader context, we surveyed $S$. salamandra rearing sites across Guadarrama N.P. for dead larvae and recently metamorphosed juveniles. Although the biology of the $B d$ amphibian interaction hypothetically allows for the observed infection dynamic, our results provide some of the first empirical evidence that intraspecific infection with $B d$ could be possible without alternative hosts and that interactions between different larval age classes play a pivotal role in $B d$ maintenance.

\section{METHODS}

\section{Study design}

Salamandra salamandra adults and larvae were sampled in 2011 at 8 larval rearing sites located in Guadarrama N.P., Central Spain $\left(40^{\circ} 50^{\prime} \mathrm{N}, 3^{\circ} 57^{\prime} \mathrm{W}\right)$. Sites were located within 800 meters of each other in the same drainage and at nearly identical elevations. Streams $(n=4)$ and ponds $(n=4)$ were evenly divided between permanent and temporary (i.e., dried completely each season) sites. Pond surface ranged from 60 to $5452 \mathrm{~m}^{2}$ and stream lengths ranging from 45.5 to $325 \mathrm{~m}$ were included. We visited each site 3 to 5 times between late May and August, weather permitting.

\section{Field methods}

\section{Density and infection surveys}


We counted all visible larvae by walking along transects that covered $\sim 90 \%$ of the stream. Ponds were small enough that we were able to walk around the entire perimeter and count all visible larvae within 1-2 $\mathrm{m}$ of the shoreline. Due to the small size of the ponds, narrowness of streams $(<1 \mathrm{~m})$ and the transparency of the water, this method provides the most accurate larval density estimates in this system (Martínez-Solano et al. 2003). To facilitate comparison between streams and ponds we converted larval counts to densities in animals $\mathrm{m}^{-1}$. We sampled any adult salamanders that we encountered within 1-2 $\mathrm{m}$ of the shoreline for evidence of infection with $B d$ by running a fine-tipped swab (MW100; Medical Wire and Equipment Ltd., Wiltshire, England) repeatedly over the epidermis of the abdominal region (10 strokes), all four limbs and digits of each foot (5 strokes/limb). Briefly, all adults and larvae were handled with a pair of powder-free nitrile gloves and although $B d$ is known to occur across the study area, gloves were changed among sites in order to avoid cross-site contamination. Using nets that were sterilized among sites, we randomly captured 20 or 40 larvae at each site, once during the spring surveys (early June) and once during the summer surveys (late August) and sampled each for evidence of infection with $B d$ similarly as described above, with the exception that the whole body of the larvae was swabbed (20 strokes total). Dry swabs were stored at $4^{\circ} \mathrm{C}$ until being processed in the laboratory. Sample sizes differed between sites based on the presence of OW larvae. Up to 40 larvae were swabbed at sites where both YoY and OW larvae occurred (i.e. permanent sites in May-June), swabbing up to 20 from each category, and up to 20 YoY were sampled at locations where OW larvae were absent (i.e. temporal sites and permanent sites in August). This is because early in the season (May-June), both overwintering larvae from the previous year and new larvae of the current year are found at permanent sites. However, later in the season (August), the overwintering larvae have metamorphosed (or died), and therefore, the sites contained only the current year larvae. OW larvae are distinguished from the small dull grayish-brown YoY by their larger body size, and blackish coloration with the presence of golden-yellowish dorsal spots on both sides of the head. All animals were unharmed and released at point of capture immediately after sampling. 
In addition, a parallel survey was conducted with the help of the local park staff to collect and collate

dead animals counts for all water bodies located within the park boundaries that have been identified as S. salamandra rearing sites. Every site was surveyed for dead larval and recently metamorphosed juveniles 6 times every year, and we report findings for the two years immediately preceding the infection survey and for that same year.

\section{Laboratory analysis}

DNA extraction and qPCR amplification was conducted following the protocol of Boyle et al. (2004) using a 96 well CFX machine (BioRad). Each sample was run in duplicate against duplicate standards of $0.1,1,10$ and 100 zoospore genomic equivalents (GE) and two negative controls. We considered an animal infected if both duplicates amplified with a mean GE of 0.1 . We used an internal positive control (IPC) to measure PCR inhibition in randomly selected samples that tested negative for $B d$ infection. Following the methodology of Hyatt et al. (2007), a VICTM labelled synthetic amplicon was used as the IPC (VICTM dye, Applied Biosystems). The IPC was included in one of each duplicate well as $1 \mu \mathrm{l} 10 \mathrm{x}$ Exo IPC mix and $0.5 \mu \mathrm{l}$ 50x Exo IPC DNA.

\section{Statistical analyses}

General Linear Mixed Models (GLMM) were applied to analyze $B d$ infection ( $B d \mathrm{I})$ dynamics in salamander larvae. The sampling site was considered as a random factor, the habitat, water permanence, larval stage and month as fixed factors, and larval density as the fixed covariate. The random factor "site" was nested within the corresponding levels of the fixed factors. The mean square (MS) and the degrees of freedom (df) of the error terms were estimated following Satterthwaite's method, which finds the linear combinations of sources of random variation that serve as appropriate error terms for testing the significance of the respective effect of interest. We used the unconstrained parameters model to test the significance of the fixed effect of the covariate, where its error term was the interaction of the covariate with the random factor "site" (Quinn \& Keough 2002). This analytical procedure is very conservative, because it solves the problem of inflated sample sizes by reducing the degrees of freedom of the error terms and avoids pseudoreplication (i.e. the proper sample unit for the 
fixed effects is the sampling locality "site" and not every salamander larvae captured in the field). $B d$ infection was transformed using the Box-Cox transformation prior to data analyses (lambda $=-1.56$; $\left.B d \mathrm{I}^{\prime}=\left[(B d \mathrm{I}+1)^{-1.56}-1\right] /-1.56\right)$. Homoscedasticity and normality of residuals of the GLMMs were checked and they did not show considerable deviations from the canonical assumptions. Due to the existence of missing cells (i.e., the lack of data at several levels of the interactions among fixed factors; e.g., 'month x larval stage', 'larval stage x permanence', 'month x permanence') three GLMM were carried out: (a) one including the whole sample of salamander larvae and all factors excluding the month, (b) another including the month but restricted to permanent sites of the permanence factor, and finally (c) one examining the $B d$ infection of YoY in August as the response to determine if $B d$ infection of OW in June was a significant predictor. In the second GLMM, we used two planned a priori comparisons to attain greater statistical power, testing for the effect of larval stage (YoY vs OW) within the sample of larvae collected in June, and testing for the effect of months (June vs August) using the sample of new YoY larvae. Data were analyzed using StatSoft's Statistica 12 (StatSoft Inc, Tulsa, Oklahoma).

\section{RESULTS}

A total of 364 larvae and 116 adults of S. salamandra were swabbed. None of the adults tested positive for infection. IPCs showed that there was no evidence of PCR inhibition in any of the samples. Table 1 shows the average figures of prevalence and infection intensity of salamander larvae (original, non-transformed data) according to habitat type, water permanence of water bodies and larval stage. The General Linear Mixed Model with all data $\left(\mathrm{F}_{12,351}=50.33, \mathrm{p}<<0.001,63.2 \%\right.$ of the variance accounted for; Table 2) showed that $B d$ infection intensity in salamander larvae was not affected by larval density, and was significantly influenced by the larval stage, type of breeding habitat and permanence. No significant differences were found across the 'site' factor in infection intensity. There were significant interactions among the fixed factors 'permanence $\mathrm{x}$ type of breeding habitat' and 'larval stage $\mathrm{x}$ type of breeding habitat'. $B d$ infection intensity was greater in 
salamanders from permanent ponds, and was absent or weak with little variation in salamanders occupying temporary water bodies and permanent streams, respectively. Also, $B d$ infection intensity of salamander larvae in ponds was greater in OW than in YoY larvae (we could not estimate the remaining interaction terms due to missing cells in the data; see Methods). Habitat type and larval stage were the predictors with the highest magnitude effects $\left(\right.$ partial $\left.\eta^{2}\right)$ that also explained the largest amount of the variance in $B d$ infection intensity, followed by the interaction term 'type of habitat $\mathrm{x}$ larval stage', while the influence of the site and the larval density inside water bodies were negligible.

The second General Linear Mixed Model showed that the effects on infection intensity of larval stage (YoY vs OW) within the sample of larvae collected in June $\left(\mathrm{F}_{1,5}=57.44, \mathrm{p}<0.001\right)$, and of months (June vs August) within the sample of new young of the year $(\mathrm{YoY})$ larvae $\left(\mathrm{F}_{1,5}=37.94, \mathrm{p}=0.002\right)$ were highly significant (after controlling for the effect of site, larval density and type of habitat; see Methods for statistical details regarding a design with missing cells). $B d$ infection intensity was greater in August than in June in new YoY salamander larvae inhabiting permanent water bodies, while $B d$ infection intensity was also greater in OW than in new YoY larvae inhabiting permanent water bodies in June.

Finally, during parallel field surveys, dead salamanders were found more frequently at locations with permanent water than at temporary ponds across Guadarrama N.P. (Table 3). Taken together, these results suggest that differences in type of breeding habitats and permanence, which foster large, overwintering larvae, were critical in driving $B d$ infection intensities.

\section{DISCUSSION}

Our results show that the type of habitat and larval stage were the most important predictors of $B d$ occurrence (which imply transmission to newly deposited larvae), and these were closely followed by the factor of water permanence (Table 2). A mechanistic link between water availability and the persistence of $B d$ is generally accepted based on the physiological needs of this fungal pathogen (Kriger \& Hero 2007). Thus, although $B d$ can persist in moist sand for extended periods of time 

that might be present in the environment given its sensitivity to desiccation (Johnson et al. 2003, Garmyn et al. 2012). At the three sites where infection persisted (i.e., two permanent ponds and one permanent stream), infection intensity in larval cohorts was significantly reduced when water was flowing rather than standing. Environmental conditions restricted to the aquatic environment can have a direct effect on transmission rate and infection dynamics by altering the density of viable zoospores (Schmeller et al. 2014). Increased water flow rate should also reduce the density of infectious particles that are available for transmission and reduce the likelihood that successful transmission will occur. In contrast, Kriger \& Hero (2007) also described a significant difference in $B d$ prevalence when comparing amphibian infection data generated from sites with standing versus flowing water, but instead found that frogs at streams were more likely to be infected than those at ponds. The difference between these two studies is likely attributable to susceptibility differences across species: post-metamorphic stages of our focal species are not carrying the fungus, whereas in Kriger \& Hero (2007) adult frogs were heavily infected. Therefore, our system excludes any influence of the terrestrial contact rates on transmission dynamics.

Despite the consistent effect of water dynamics on infection in our system, the necessity of an aquatic environment for the survival and persistence of $B d$ has been challenged by detection of infection in strictly terrestrial amphibian species (e.g. Weinstein 2009). Permanent water is also not a guarantee for zoospore survival (Schmeller et al. 2014). Although recent evidence suggested that $B d$ can persist in the water through the year in pond habitats, the detection probability of $B d$ increased as density of amphibians increased at the sampling sites (Chestnut et al. 2014). Thus, efforts to detect environmentally persistent forms of the fungus in aquatic habitats (including water bodies in Guadarrama N.P.) suggest that persistence outside the host in water is limited and that detection of $B d$ in aquatic environments is predicated on the presence of infected animals at the time of sampling (Kirshtein et al. 2007, Walker et al. 2007, Hossack et al. 2009). Certainly, the lack of transmission to YoY at ephemeral sites cannot be directly attributed to pond or stream drying over the course of our field season, as water was present at all four sites during our August surveys. We can also eliminate 
the potential for vertical transmission, as none of the adults we sampled in the area exhibited detectable infections. Instead, our data suggest that OW larvae -which did not occur at ephemeral sites as drying either forced larvae to complete metamorphosis or die, leaving these sites unoccupied for the incoming cohort of larvae in the subsequent year- drive infection dynamics in this system. We conclude that the effect of water permanence on infection dynamics was potentially driven through its direct effect on the presence of the intraspecific reservoir OW larvae. As argued in Fisher et al. (2009), the amphibian host is the primary environment for $B d$, thus maintenance of infection in a host species and its ability to transmit infection to susceptible hosts should be the most important predictors of pathogen persistence.

Field experiments investigating transmission probabilities of $B d$ in larval populations have shown that site effects are interactive with host density (Rachowicz \& Briggs 2007). This may go some way to explaining why larval abundance was not an important factor affecting infections in our system, which should be the case if transmission was density-dependent (Table 2). The few attempts that have been made to determine the transmission function of $B d$ are inconsistent in their support of wholly density-dependent transmission (Rachowicz \& Briggs 2007, Briggs et al. 2010). The probability of transmitting $B d$ resulting in sustained infections may instead be more strongly affected by factors that influence the frequency of individual transmission events, such as temperature (FernándezBeaskoetxea et al. 2015), rather than the frequency of individual transmission events alone. Infections in even highly susceptible host species are often lost then reacquired through subsequent re-exposure, and threshold burdens are associated with clearance and maintenance of infection, as well as host mortality; burdens that are realized through re-exposure and re-infection (Briggs et al. 2010, Vredenburg et al. 2010).

Although the presence of OW larvae strongly influences transmission to YoY larvae at our study sites, transmission to and reinfection of YoY is likely a process that continues after OW larvae have completed metamorphosis. Infection intensity of larval cohorts was weak at permanent stream sites and remains so across the season, which we attribute to the diluting effect of running water. In comparison, significant amplification of infection intensity in YoY larvae, between June and August 
in permanent ponds, indicates that the processes of transmission and intensification of infections are better supported in permanent ponds and ongoing across the sampling period. Permanent stream sites therefore represent a riskier environment for age-specific, single host species maintenance of $B d$ in Guadarrama N.P. Nevertheless, YoY sampled at the end of the season in ponds with permanent water exhibited weaker infections than their OW reservoir counterparts at the beginning of the sampling period. Thus, although our study did not look at interannual patterns of infections, we would expect that in the following year the remaining larvae will exhibit higher infection levels (i.e., similar to those of the OW we sampled).

Although we conclude that $B d$ infection can be maintained in $S$. salamandra populations through intraspecific transmission among larval age classes, it remains unresolved whether infection can be sustained over the long term exclusively in this species without the benefit of an interspecific or environmental reservoir. Our study indicates that intraspecific dynamics at permanent streams are more likely to favour host persistence due to decreased intensity of infections compared to permanent ponds, and in the long run might also favour pathogen fade out. Transmission dynamics at ponds instead favour pathogen persistence over the short term. Importantly, declines of S. salamandra were documented predominantly at pond locations and local extirpation associated with chytridiomycosis was recorded at many of these ponds (Bosch \& Martínez-Solano 2006). Salamanders are still dying due to chytridiomycosis, and at much higher rates at locations with permanent water (Table 3). Extirpation of OW larvae from a pond site could presumably be compensated for through recruitment, but without the reservoir, the persistence of $B d$ at such a location seems highly unlikely. Overall, while the maintenance of $B d$ infection in $S$. salamandra without an exogenous source of infection in sites with OW larvae appears possible from our study, for the long term, the strategy is risky for the pathogen.

Persistence of S. salamandra at Guadarrama N.P. is also uncertain. Our survey data shows that the mortality rate that likely contributed to previously recorded extirpations is ongoing (Table 3). Salamandra salamandra existence at higher elevations is closely linked to the ability of larvae to delay metamorphosis and as we have shown this strategy requires that water be available throughout 
the year. Ponds are a more reliable permanent water body than streams, as they are far more common in the park, and far less likely to dry out than streams. If $B d$ does render these locations unavailable to S. salamandra larvae, the overwintering strategy will be far less suitable. Notwithstanding, there is reason to be more optimistic than when $B d$ was first detected in the park (Bosch et al. 2001). Salamanders were thought to be in decline in Guadarrama N.P. and infection with $B d$ was considered to be the culprit (Bosch \& Martínez-Solano 2006), but more recent surveys suggest that the park population may be at a relatively stable equilibrium (J. Bosch, unpublished data). Although adult salamanders are susceptible to lethal disease under high $B d$ intensity (Bosch \& Martínez-Solano 2006), after the near extirpation of $A$. obstetricans from our study sites they appear not to contract infections. Irrespective, persistence of $B d$ and S. salamandra at Guadarrama N.P. cannot be predicted based on intraspecific infection and transmission dynamics. Within this context, the recently described amphibian pathogen, Batrachochytrium salamandrivorans (Bsal), although not present at this point at the study site (Martel et al. 2014), would potentially affect the interaction between $B d$ and $S$. salamandra due to its high virulence to $S$. salamandra and lower thermal range for optimal growth compared to $B d$ (Martel et al. 2013).

Considering the infection dynamic we described and the threat posed by $B s a l$, mitigation strategies at the Guadarrama N.P. to allow future amphibian reintroductions should focus on the life-history stages that undergo extended periods of exposure to the pathogen (Scheele et al. 2014). Therefore, reducing transmission events between larval stages of $S$. salamandra at permanent ponds could be an effective starting point, while also assuring the conservation of habitats (with established S. salamandra larvae populations) that are unsuitable for $B d$ transmission, such as permanent streams. On the other hand, Guadarrama N.P. is host to several other amphibian species, including hosts that can harbour infections. Whatever the fate of $B d$ in single host species populations, it is unlikely to be extirpated from the area and the pattern of amphibian host decline still continues. 
308

309

310

311

312

We thank J. L. Hite for statistical advise and field assistance, S. Fernández-Beaskoetxea for field assistance, the people working at the Guadarrama National Park for field data, facilities and permits, and Fundación General CSIC, Banco Santander and BioDiversa project RACE for financial support.

\section{BIBLIOGRAPHY}

Agrawal AA (2000) Host-range evolution: adaptation and trade-offs in fitness of mites on alternative hosts. Ecology 81:500-508

Bartlett MS (1960) The critical community size for measles in the United States. J R Stat Soc A $123: 37-44$

Bosch J, Martínez-Solano I (2006) Chytrid fungus infection related to unusual mortalities of Salamandra salamandra and Bufo bufo in the Penalara Natural Park, Spain. Oryx 40:84-89

Bosch J, Martínez-Solano I, García-París M (2001) Evidence of a chytrid fungus infection involved in the decline of the common midwife toad (Alytes obstetricans) in protected areas of central Spain. Biol Conserv 97:331-337

Boyle DGD, Boyle DBD, Olsen VV, Morgan JATJ, Hyatt ADA (2004) Rapid quantitative detection of chytridiomycosis (Batrachochytrium dendrobatidis) in amphibian samples using real-time Taqman PCR assay. Dis Aquat Org 60:141-148

Briggs CJ, Knapp RA, Vredenburg VT (2010) Enzootic and epizootic dynamics of the chytrid fungal pathogen of amphibians. Proc Natl Acad Sci USA 107:9695-9700

Briggs CJ, Vredenburg VT, Knapp RA, Rachowicz LJ (2005) Investigating the population-level effects of chytridiomycosis: an emerging infectious disease of amphibians. Ecology 86:31493159 
Brunner JL, Schock DM, Davidson EW, Collins JP (2004) Intraspecific reservoirs: complex life history and the persistence of a lethal ranavirus. Ecology 85:560-566

Chestnut T, Anderson Ch, Popa R, Blaustein AR, Voytek M, Olson DH, Kirshtein J (2014) Heterogeneus occupancy and density estimates of the pathogenic fungus Batrachochytrium dendrobatidis in waters of North America. PloS ONE 9:e106790

De Castro F, Bolker B (2005) Mechanisms of disease-induced extinction. Ecol Lett 8:117-126

Fernández-Beaskoetxea S, Carrascal LM, Fernández-Loras A, Fisher MC, Bosch J (2015) Short term minimum water temperatures determine levels of infection by the amphibian chytrid fungus in Alytes obstetricans tadpoles. PLoS ONE 10:e0120237

Fisher MC, Garner TWJ, Walker SF (2009) Global Emergence of Batrachochytrium dendrobatidis and Amphibian Chytridiomycosis in Space, Time, and Host. Annual Review of Microbiology $63: 291-310$

Fisher MC, Henk DA, Briggs CJ, Brownstein JS, Madoff LC, McCaw SL, Gurr SJ (2012) Emerging fungal threats to animal, plant and ecosystem health. Nature 484:186-194

Fuller E, Elderd BD, Dwyer G (2012) Pathogen persistence in the environment and insectbaculovirus interactions: disease-density thresholds, epidemic burnout, and insect outbreaks. The Am Nat 179:E70-E96

Garmyn A, Van Rooij P, Pasmans F, Hellebuyck T, Van Den Broeck W, Haesebrouck F, Martel A (2012) Waterfowl: potential environmental reservoirs of the chytrid fungus Batrachochytrium dendrobatidis. PLoS ONE 7:e35038

Garner TWJ, Perkins MW, Govindarajulu P, Seglie D, Walker S, Cunningham AA, Fisher MC (2006) The emerging amphibian pathogen Batrachochytrium dendrobatidis globally infects introduced populations of the North American bullfrog, Rana catesbeiana. Biol Lett 2:455-459 
Batrachochytrium dendrobatidis: a case study in the Rocky Mountains, USA. J Wildl Dis 45:1198-1202

Hyatt AD, Boyle DG, Olsen V, Boyle DB, Berger L, Obendorf D, Dalton A, Kriger K, Hero M, Hines H, Phillott R, Campbell R, Marantelli G, Gleason F, Colling A (2007). Diagnostic assays and sampling protocols for the detection of Batrachochytrium dendrobatidis. Dis Aquat Org $73: 175-192$

Johnson ML, Speare R (2005) Possible modes of dissemination of the amphibian chytrid Batrachochytrium dendrobatidis in the environment. Dis Aquat Org 65:181-186

Johnson ML, Berger L, Phillips L, Speare R (2003) Fungicidal effects of chemical disinfectants, UV light, desiccation and heat on the amphibian chytrid, Batrachochytrium dendrobatidis. Dis Aquat Org 57:255-260

Kirshtein JD, Anderson CW, Wood JS, Longcore JE, Voytek MA (2007) Quantitative PCR detection of Batrachochytrium dendrobatidis DNA from sediments and water. Dis Aquat Org 77:11-15

Kriger KM, Hero J-M (2007) The chytrid fungus Batrachochytrium dendrobatidis is non-randomly distributed across amphibian breeding habitats. Diversity Distrib 13:781-788

Martel A, Spitzen-van der Sluijs A, Blooi M, Bert W, Ducatelle R, Fisher MC, Woeltjes A, Bosman W, Chiers K, Bossuyt F, Pasmas F (2013) Batrachochytrium salamandrivorans sp. nov. causes lethal chytridiomycosis in amphibians. Proc Natl Acad Sci USA 110:15325-15329

Martel A, Blooi M, Adriaensen C, Van Rooij P, Beukema W, Fisher MC, Farrer RA, Schmidt BR, Tobler U, Goka K, Lips KR, Muletz C, Zamudio KR, Bosch J, Lötters S, Wombwell E, Garner TWJ, Cunningham AA, Spitzen-van der Sluijs A, Salvidio S, Ducatelle R, Nishikawa K, Nguyen TT, Kolby JE, Van Bocxlaer I, Bossuyt F, Pasmas F (2014) Recent introductions of a chytrid fungus endangers Western Paleartic salamanders. Science 346:630-631 
Quinn GP, Keough MJ (2002) Experimental Design and Data Analysis for Biologists. Cambridge University Press, Cambridge

Rachowicz LJ, Briggs CJ (2007) Quantifying the disease transmission function: effects of density on Batrachochytrium dendrobatidis transmission in the mountain yellow-legged frog Rana muscosa. J Anim Ecology 76:711-721

Reeder NMM, Pessier AP, Vredenburg VT (2012) A reservoir species for the emerging amphibian pathogen Batrachochytrium dendrobatidis thrives in a landscape decimated by disease. PLoS ONE 7:e33567

Ruiz-González MX, Bryden J, Moret Y, Reber-Funk C, Schmid-Hempel P, Brown MJF (2012) Dynamic transmission, host quality, and population ptructure in a multihost parasite of bumblebees. Evolution 66:3053-3066

Scheele BC, Hunter DA, Grogan LF, Berger L, Kolby JE, McFadden MS, Marantelli G, Skerratt LF, Driscoll DA (2014) Interventions for reducing extinction risk in chytridiomycosis-threatened amphibians. Conserv Biol 28:1195-1205

Schmeller DS, Blooi M, Martel A, Garner TWJ, Fisher MC, Azerman F, Clare FC, Leclerc C, Jäger L, Guevara-Nieto M, Loyau A, Pasmas F (2014) Microscopic aquatic predators strongly affect infection dynamics of a globally emerged pathogen. Curr Biol 24:176-180

Schmidt BR, Schaub M, Steinfartz S (2007) Apparent survival of the salamander Salamandra salamandra is low because of high migratory activity. Front Zool 4:19

Vredenburg VT, Knapp RA, Tunstall TS, Briggs CJ (2010) Dynamics of an emerging disease drive large-scale amphibian population extinctions. Proc Natl Acad Sci USA 107:9689-9694

Wake MH (1993) Evolution of oviductal gestation in amphibians. J Exp Zool 266:394-413 

Aquat Org 77:105-112

404 Walker SF, Bosch J, Gomez V, Garner TWJ, Cunningham AA, Schmeller DS, Ninyerola M, Henk DA, Ginestet C, Arthur C-P, Fisher MC (2010) Factors driving pathogenicity vs. prevalence of amphibian panzootic chytridiomycosis in Iberia. Ecol Lett 13:372-382

407 Weinstein SB (2009) An aquatic disease on a terrestrial salamander: individual and population level effects of the amphibian chytrid fungus, Batrachochytrium dendrobatidis, on Batrachoseps attenuatus (Plethodontidae). Copeia 2009:653-660. 
412 Table 1. The effect of habitat type (pond / stream), water permanence (temporary / permanent) of

413 water bodies and larval stage (young of year, YoY / overwintered, OW) on prevalence and $B d$

414 infection intensity of salamander larvae (mean and SD of zoospore genomic equivalents). N: number

415 of salamander larvae.

416

417 Permanence Habitat Larval stage N Prevalence Infection intensity

418

mean SD

419

Permanent Pond

40

0.975

38.47

34.02

420

Permanent

Pond

YoY

80

0.438

5.17

18.09

421

Permanent

Stream

OW

40

0.075

0.41

1.46

422

Permanent

Stream

YoY

80

0.063

0.05

0.35

423 Temporary

Pond

OW

not applicable

424 Temporary

Pond

YoY

60

0.000

0.00

0.00

425 Temporary

Stream

OW

not applicable

426

Temporary

Stream

YoY

64

0.000

0.00

0.00

427 
428 Table 2. Results of a general linear mixed-model of $B d$ infection in salamander larvae (Box-Cox

429 transformed) in relation to larval density (fixed covariate), type of habitat (pond vs stream),

430 permanence (permanent vs temporary), and larval stage (young of year vs overwintered larvae) as

431 fixed factors, and site as a random factor (nested within the levels of the previous fixed factors). The

432 effect sizes are also given as \% of variance explained (according to sum of squares) and partial $\eta 2$.

433 The interaction terms 'permanence $\mathrm{x}$ type of habitat' and 'larval stage $\mathrm{x}$ type of habitat' were only

434 estimated considering the missing cells design. Denominator degrees of freedom have been rounded

435 to the nearest unit. For more details on error term definitions, see Methods.

\begin{tabular}{lrrrrrr} 
& Sum of squares & $\%$ variance & partial $\eta^{2}$ & df & F & p \\
\hline Larval density & 0.001 & 0.00 & 0.000 & 1,6 & 0.03 & 0.864 \\
Permanence (P) & 0.712 & 3.41 & 0.784 & 1,6 & 23.38 & 0.002 \\
Type of habitat (TH) & 2.847 & 13.63 & 0.882 & 1,14 & 105.50 & $<0.001$ \\
Larval stage (LS) & 2.261 & 10.82 & 0.921 & 1,6 & 73.94 & $<0.001$ \\
$\mathrm{P} *$ TH & 0.587 & 2.81 & 0.756 & 1,6 & 19.09 & 0.004 \\
LS * TH & 1.670 & 7.99 & 0.896 & 1,6 & 54.63 & $<0.001$ \\
Site & 0.185 & 0.89 & 0.024 & 6,351 & 1.41 & 0.209 \\
\hline
\end{tabular}


Table 3. Counts of ponds located in Guadarrama National Park occupied by S. salamandra larvae of any age class. Counts are split by water permanence and data are summed across 3 year's sampling (2009-2011). Numbers in parenthesis are the number of carcasses counted across all ponds in a given water permanence category.

\begin{tabular}{lcccc}
\hline & $\begin{array}{c}\text { Number of } \\
\text { ponds }\end{array}$ & $\begin{array}{c}\text { Ponds with larvae } \\
\text { of any age class }\end{array}$ & $\begin{array}{c}\text { Ponds with only } \\
\text { overwintered larvae }\end{array}$ & Ponds with observed \\
& 29 & 29 & 21 & $7(58)$ \\
Permanent & 213 & 153 & 0 & $1(1)$ \\
Temporary & & & & \\
\hline
\end{tabular}

